\title{
Effects of VH-iSTEM Learning Strategy on Basic Secondary School Students' Degree of Acquisition of van Hiele Levels of Thinking in Sokoto State, Nigeria
}

\author{
Muhammad Nasiru Hassan $^{1,2, *}$, Abdul Halim Abdullah $^{2}$, Norulhuda Ismail ${ }^{2}$ \\ ${ }^{1}$ Department of Science Education, Faculty of Education Sokoto, State University, Nigeria \\ ${ }^{2}$ School of Education, Faculty of Social Sciences and Humanities, Universiti Teknologi Malaysia, Malaysia
}

Received June 15, 2020; Revised July 20, 2020; Accepted August 25, 2020

\section{Cite This Paper in the following Citation Styles}

(a): [1] Muhammad Nasiru Hassan, Abdul Halim Abdullah, Norulhuda Ismail , "Effects of VH-iSTEM Learning Strategy on Basic Secondary School Students' Degree of Acquisition of van Hiele Levels of Thinking in Sokoto State, Nigeria," Universal Journal of Educational Research, Vol. 8, No. 9, pp. 4213-4223, 2020. DOI: 10.13189/ujer.2020.080948.

(b): Muhammad Nasiru Hassan, Abdul Halim Abdullah, Norulhuda Ismail (2020). Effects of VH-iSTEM Learning Strategy on Basic Secondary School Students' Degree of Acquisition of van Hiele Levels of Thinking in Sokoto State, Nigeria. Universal Journal of Educational Research, 8(9), 4213-4223. DOI: 10.13189/ujer.2020.080948.

Copyright $\bigcirc 2020$ by authors, all rights reserved. Authors agree that this article remains permanently open access under the terms of the Creative Commons Attribution License 4.0 International License

\begin{abstract}
Learning school geometry and development of geometric thinking skills required a careful selection of strategy, that provides collaborative learning behaviors, use of appropriate tasks, and materials. Thus, teaching and learning should be meaningful not just merely transmission and absorption. Hence opportunities should be given for students to experiment and discover learning experience by themselves. This study investigated the effect of instructional strategy (VH-iSTEM) designed to help in solving the problems of learning school geometry and develop students' geometric thinking skills. The strategy emphasized the learning of geometry based on the connections of the iSTEM (engineering design phase) with the van Hiele phase. A quasi-experimental, design was used in this study with a sample of 89 students divided into two experimental groups of 30 each (VH-iSTEM, and VH); and 29 students in the control group. Additionally, three students were randomly selected from each group for an interview. The qualitative results obtained revealed that the majority of the students at pre-interview were able to achieve complete acquisition of level one of thinking and that, six students achieve low acquisition of level two, with no acquisition of level three among three independent groups. Thus, after the intervention, only students in the VH-iSTEM learning strategy group achieved the complete acquisition of level one to level three of van Hiele levels. Two students achieved a lower acquisition of level three and that one student achieved the high acquisition of level
\end{abstract}

two and level three in the $\mathrm{VH}$ group. No students achieved level three in the control group. This demonstrates that VH-iSTEM learning strategy can be applied in classroom instruction to help students achieve a higher level of geometric thinking.

Keywords Geometric Thinking, Basic Secondary School Students, VH-iSTEM Strategy

\section{Introduction}

In the Nigerian educational system, the geometric topics are given much emphasis at all levels of education. The geometric thinking (GT) skills provided in the New Mathematics Curriculum for all the levels are spiral, that is what is at lower basic education is the same to other levels but with different complexity. The basic geometric concepts and thinking skills that involve identification and naming of a geometric figure (level 1 of GT); properties, and classification (level 2 of GT) are introduced at the lower basic level. in addition to basic GT skill proving of Euclidean geometry (level $3 \& 4$ of GT), are emphasized at senior secondary school, as well as solving a practical problem, that includes coordinate geometry, and identification of distances between two points (Federal Republic of Nigeria, 2012). On top of that, formula 
derivation is emphasized upper basic level using informal justification, while proofs of the theorem are emphasized in senior secondary school. Students will be guided to use deduction or step-wise logical reasoning to arrive at a valid conclusion (ibid). It is evidenced that $35 \%-40 \%$ or one-third of the questions asked by the examination bodies in Nigeria are made-up of geometric problems [2]. Geometric experience enables us with those abilities to identify, analyze, and understand our physical environments [3]. This could be the reason why geometry became the central element of the mathematics curriculum. According to [4] Geometry should be considered in the mathematics curriculum thought out the levels.

However, the current learning process used in Nigeria does not help in actualizing the objectives given to geometry in the mathematics curriculum, this is because, the learning process is based on textual representation, explanation of concepts with definitions; use of algorithms, and memorization of theories without understanding the rationale. Atebe \& Schäfer (2011) affirmed that the nature of the instructional process in Nigeria remained traditional. Based on the analysis, of sample teachers in their classroom instruction, the introduction of the lesson was performed without relating to the prior knowledge of the learners; and geometric concepts are stated by the teacher not developed. More so, $80 \%$ of the lesson is dominated by the teacher without the active involvement of the learner (ibid). Studies show that the teaching and learning process in Nigerian schools remained traditional [6]-[8]. Ugboduma (2017) maintained that this mode of instruction and learning strategy (conventional) failed to meet the needs of society. Rohani, Abdul Halim, Mohd Salleh, Mahani, \& Noor Azean,[10] affirmed that this method is inappropriate in teaching and learning geometry because it failed to improve higher-order thinking. In other words, the conventional method cannot provide the required skills that enhance the critical thinking of learners, problem-solving, and that little contribution towards improving geometric thinking could be achieved. Lipowsky, Rakoczy, Pauli, Drollinger-vetter, Klieme \& Reusser [11] pointed out that instructional activity that stimulates learners to share ideas and compare their thoughts about concepts and solving problems with challenging activities can help in developing cognitive activation. Thus, if the instructional process only requested students to use a standard procedure explained by the teacher based on the transmission (teacher) of the learning experience and absorption by the learners, it leads to a low level of understanding (ibid). In other words, the learning process used could create a gap in students' geometric thinking levels from a lower level to a subsequent higher level of the van Hiele levels; difficulty with learning, and lower level of geometric thinking skills of students in Nigeria.

\section{Difficulties of Students with Geometric Thinking Skills}

Difficulties with geometry and lower level of geometric thinking (GT) continue to be a topical issue not only in Nigeria but in many countries. $52 \%$ of students could not calculate the area of the square and $70 \%$ of them graduated operating from level 1- level 3 in the United States[12]. Recently, literature indicated the continuation of the problem in difficulties with geometry [13]-[16]. Similarly, research studies in Nigeria indicated that 63\% of students demonstrated a serious problem with difficulties in geometry and lower level of GT skills [17] and $57 \%$ of the students in Nigeria are operating at the pre-recognition level and that only $2 \%$ and $3 \%$ can achieve level 2 and level 3 of GT [18]. Thus, some of the issues associated with the problem are the mode of instruction, negative attitude, and mismatch of thinking between teacher and students.

However, learning school geometry and the development of geometric thinking skills particularly at a lower level of schooling required a careful selection of materials, appropriate tasks, use of manipulatives, and engagement of students in the learning process. Van de Walle, [19] pointed out that, use of interactive learning, hands-on and reflective in the learning process at elementary and middle school is the key to the successful development of GT. Lipowsky et al.,[11] affirmed that the achievement of students is dependent on the opportunity given to students to learn by themselves as explained by the researchers in mathematics education. Thus, in this research, a learning strategy that provides collaborative learning behavior, experiential activity, and scaffolding called VH-iSTEM was developed to solve the problem of difficulty and improve the geometric thinking skills of students in Sokoto state Nigeria.

\subsection{Current Study}

The present research was done to evaluate the effectiveness of the VH-iSTEM strategy, comparing three independent groups using three different instructions that include, VH-iSTEM, VH (van Hiele model) along and Conventional classroom instruction. Three levels of van Hiele levels are considered based on plane shapes. Also, a focus was given to investigate the students' degree of acquisition of van Hiele levels. To achieve these, research questions were generated.

\subsection{Research Questions}

To achieve the objectives of the present research, research questions were provided to guide the researchers. The research question investigates the students' degree of acquisition for the van Hiele levels of GT before and after the intervention. The investigation involves the three independent groups. 


\section{Methodology}

\subsection{Design}

A quasi-experimental design of pre-test post-test, non-randomized control group type was used in this study [20]. The design is dependent upon the natural setting in which the researcher finds himself [21].

\subsection{Participants}

Participants in the present research were drowned from basic secondary school students in Sokoto state Nigeria. A total of 89 students were involved in this study. The sample involves three randomly selected students each among the three independent groups for the interview to elucidate the students' degree of acquisition based on the van Hiele levels of geometric thinking.

\subsection{Ethical Consideration}

The research starts the process by giving a letter of introduction to the Sokoto State Ministry for Basic and Secondary Education and a letter seeking permission to undertake the research. All the participants (teachers and students) were told that their names and name of the school, would be kept confidential and anonymous. As such all the participating students, mathematics teachers, as well as the school name, appear in this research report as pseudo. A concern form was given to mathematics teacher that volunteer to participate throughout the research and a letter was given to the parents of the students for their concern about the involvements of their wards in this study.

\subsection{Intervention Fidelity}

To ensure the fidelity of the intervention, the instruction for $80 \mathrm{~min}$. lesson activities were plan based on the structure of the VH-iSTEM learning strategy (see Table 1). Group of five students was used in the learning process using collaborative learning behaviors, participatory activity, use of interrogative questions, sharing of ideas, and helping students to discover learning experience by themselves.

More so, students are expected to record their findings based on challenging activities. The process was done based on the lesson activities and that the teachers act as a facilitator to provide scaffolding to students. More so, lesson activities were scripted to ensure the instructional consistency, and that similarity in the lesson content, and activities across all the three independent groups, were evaluated and rated independently by five experts. The result indicates an $80 \%$ percentage absolute agreement with Cronbach alpha of 0.97 using the intraclass correlation coefficient of the two-way random-effect model based on the ratings of the five experts. Thus, the direct observation method was used in assessing the fidelity of the intervention. The method was used [5]. Therefore, in this research, the process was adapted and used to ensure the achievement of the critical features of intervention and how to teach the students.

Table 1. Descriptions of the connections of van Hiele and engineering design phases

\begin{tabular}{|c|c|c|}
\hline \multicolumn{2}{|c|}{ Phases } & Description of the connections \\
\hline Information & Ask & $\begin{array}{l}\text { Information phase/ Ask: At this phase interaction and discussions are emphasized between } \\
\text { the students and the teacher; challenging activity to discover the possibility of doing } \\
\text { something by imposing problems to students with the questions like can you, is it possible to } \\
\text { so that students can start thinking for the possibility of doing the given problem. For } \\
\text { example, to concretize the interactions and discussion among students and teacher a } \\
\text { challenging activity that involves physical observation to discover some geometric shapes } \\
\text { in the classroom or outside the class, draw the shapes in accordance with their appealing are } \\
\text { emphasized. }\end{array}$ \\
\hline Guided orientation & $\begin{array}{c}\text { Imagine } \\
\text { Plan } \\
\text { Create }\end{array}$ & $\begin{array}{l}\text { Students are guided to interact, brainstorm, and follow their plan to create or do a given task } \\
\text { or challenging activity by themselves. Some of the activities include open-ended } \\
\text { challenging activities like the use of puzzles to provide the opportunities for the students to } \\
\text { build, make, draw, put together and take part of a figure to develop new shapes; construction } \\
\text { of tiles challenging activity with geometric shapes. }\end{array}$ \\
\hline \multicolumn{2}{|c|}{ Explanation } & $\begin{array}{l}\text { Questions that clarify the students' imprecise terminology are emphasized and a gradual } \\
\text { introduction of correct and formal mathematics language. }\end{array}$ \\
\hline \multicolumn{2}{|c|}{ Free orientation } & $\begin{array}{l}\text { Complex activity will be given to learn and establish the network for the features in a given } \\
\text { shape. Some activities include the construction of mast (tower) challenging activity with a } \\
\text { different base (triangular, square) are emphasized. Open-ended questions will be used and } \\
\text { encourage students to discover given shapes and provide connections in terms of } \\
\text { relationships, differences, and classification of geometric shapes based on characteristics } \\
\text { using their ideas. }\end{array}$ \\
\hline Integration & Improve & $\begin{array}{l}\text { Questions are used to encourage students to make reflection refine and summarized the } \\
\text { experience gain about the concept learned. }\end{array}$ \\
\hline
\end{tabular}




\subsection{Measures}

\subsubsection{Measuring students' degree of acquisition based on} van Hiele levels of geometric thinking

Students' van Hiele level of geometric thinking is assessed using two methods. The first is the use of quantitative data (test) based on the instrument develops by Cognitive Development and Achievement in Secondary School Geometry [12].

The second method used is the interview (qualitative) as proposed by [22] to determine students' degree of the acquisition of van Hiele levels of thinking. Thus, to ascertain the students' level of geometric thinking, pre, and post-interview were done and transcribed at the first stage, the result of the answers obtained was used and determined the students' degree of the acquisition on the van Hiele level of geometric thinking. Thus each answer provided by the students was assigned to one of eight types ( $t$ ) of answers (see Table 2) as proposed by [22]. The scoring of answers is depending on the accuracy and degree of reasoning completed by the student. Finally, appropriate vector quantity $(1, t)$ that is level and type for all answered items on a particular level was identified (see Table 3), and then a students' van Hiele levels and degree of the acquisition were obtained by calculating the average (mean) value for each level and also, the students' van Hiele's degree of acquisition value was determined (see Figure 1), for more detailed about the criteria in [22].

Table 2. Descriptions of each type of answers

\begin{tabular}{|l|l|}
\hline Type answer & Description \\
\hline Type 0 & No reply or answer that cannot be codified. \\
\hline Type 1 & Answers that indicate the learner has not attained a given level but that gives no information about any lower level. \\
\hline Type 2 & $\begin{array}{l}\text { Wrong and insufficiently work out answers that give some indication of a given level of reasoning; answers that contain } \\
\text { incorrect and reduced explanations, reasoning processes, or result. }\end{array}$ \\
\hline Type 3 & $\begin{array}{l}\text { Correct but insufficiently worked out answers that give some indication of a given level of reasoning; answers that contain } \\
\text { very few explanations, inchoate reasoning processes, or very incomplete results. }\end{array}$ \\
\hline Type 4 & $\begin{array}{l}\text { Correct or incorrect answers that clearly reflect the characteristic feature of two consecutive van Hiele's levels and that } \\
\text { contain clear reasoning processes and sufficient justifications. }\end{array}$ \\
\hline Type 5 & $\begin{array}{l}\text { The incorrect answer that clearly reflects a level of reasoning; answers that present reasoning processes that are complete } \\
\text { but incorrect or answer that present correct reasoning processes that do not lead to the solution of the stated problems. }\end{array}$ \\
\hline Type 6 & Correct answers that clearly reflect a given level of reasoning but that are incomplete or insufficiently justified. \\
\hline Type 7 & Correct complete and sufficiently justified answers that clearly reflect a given level of reasoning. \\
\hline
\end{tabular}

Table 3. Weights of different type of answers

\begin{tabular}{|c|c|c|c|c|c|c|c|c|}
\hline Type & 0 & 1 & 2 & 3 & 4 & 5 & 6 & 7 \\
\hline Weight & 0 & 0 & 20 & 25 & 50 & 75 & 80 & 100 \\
\hline
\end{tabular}

Source (Gutierrez et al., 1991)

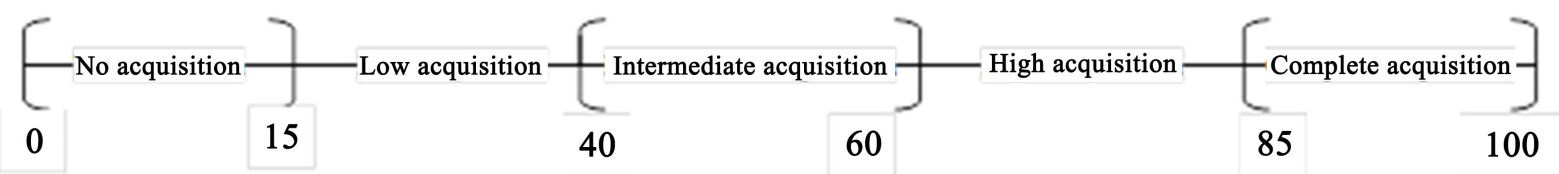

Figure 1. Degrees of acquisition of a Van Hiele level Source (Gutierrez et al., 1991) 


\section{Results}

Based on the objective of the present research the characteristics of students' levels of geometric thinking was obtained using interview, to provide the qualitative results. Thus, 9 students were involved in the interview three students in each group, letter A-I was used to describe the profile of the students. In this study, the researchers only presented the answers provided by three students one in each group. For the pre-interview students $\mathrm{D}$ and $\mathrm{G}$ from $\mathrm{VH}$ and Control group, while a post-interview answer of students $\mathrm{A}$ in the VH-iSTEM group was presented. For the pre-interview answers provided by student $\mathrm{D}$. for the first item that required the student to provide name, draw and construct the geometric figure was given, therefore, student $\mathrm{D}$ provide the name of figure as square and draw the rectangle, for this a vector of $(1,7)$ was assigned. For item 4 , that required students to provide the properties, Student D asked, as look at this figure you constructed on the geoboard what you can tell me if I want to know it is a rectangle and provide an answer as .... I think the two sides are the same and remained silent. For this answer, a vector of $(2,3)$ and $(1$, 7) was assigned, because the correct answer was given but contained few explanations. Some of the required answers are all the angles are $90^{\circ}$, two-line of symmetry, two opposite sides are equal, etc. For item5 Student D was asked to provide similarities and differences using justification, for square and rhombus, after a prolonged silence and then said, the difference is that lines in the square are straight while for the rhombus it bends. Is that all you can say? Therefore, the answers are based on photo-type without any justification, as such a vector of $(0$, $0),(2,3)$ and $(1,7)$. Table 4 provides the summary of the student D level on van Hiele degree of acquisition as provided in figure 1 reference with the mean obtained.

For student $G$ in the control group was asked to construct a triangle and the student manages to construct the triangle correctly on the geoboard and a vector of $(1,7)$ was assigned. For item 4 the researcher asks the student $G$, as what can you tell me to understand this triangle is right angle triangle after prolong silent the student said it had three angles. Anything you can tell me? No. Therefore, a vector of $(2,3)$, and $(1,7)$ was assigned, because the answer is insufficient. For item 5 question was asked to provide the general name of a figure with four sides, the student remains silent without answer, and also cannot provide the difference between the shapes (square and rhombus) a vector of $(0.0),(0,0)$ and $(1,7)$ was assigned. Table 5.

For the post-interview, student $\mathrm{A}$ in the VH-iSTEM group interview results is presented as well as the level of the acquisition obtained based on the answers provided. For the item that requires the student to provide names, draw and construct the geometric figure, a vector of $(1,7)$ was assigned to student $\mathrm{A}$ for the answer given. The student manages to provide the names of the geometric figures constructed on geoboard using appropriate terminology as square, rectangle, rhombus... among others. For the item that required the students to explain the properties. Student A responds...... as the square has four equal sides, the diagonal bisects each other, at $90^{\circ}$, and the two sides are parallel. The research also asked how do you know is $90^{\circ}$, because their diagonal bisect each other and also if you use the protractor and measure. Therefore, a vector of $(2,7)$ and $(1,7)$ was assigned. For item 5 that required informal justification, a vector of $(3,7),(2,7)$, and $(1,7)$. Some of the answers provided for the similarities of square and rectangle include, ...... the two have four (4) sides and angles for the difference the student A answers are .....rectangle two opposite side are equal while square all the sides are the same, two-line of symmetry [rectangle] and four-line of symmetry [square]. Table 9 provides a summary.

Table 4. Pre-level weights of acquisition for student $\mathrm{D}$ geometric thinking

\begin{tabular}{|c|c|c|c|c|c|c|c|c|c|c|c|c|c|}
\hline \multirow{2}{*}{ Student ID } & \multirow{2}{*}{ Levels } & \multicolumn{10}{|c|}{ Items } & Mean & \multirow{2}{*}{ Degree } \\
\hline & & 1 & 2 & 3 & 4 & 5 & 6 & 7 & 8 & 9 & 10 & & \\
\hline \multirow[t]{3}{*}{ Student D } & One & 100 & 100 & 100 & 100 & 100 & 100 & 100 & 100 & 100 & 100 & 100 & Complete \\
\hline & Two & - & - & 25 & 25 & 0 & - & - & 25 & 25 & 0 & 17 & Low \\
\hline & Three & - & - & -- & - & 0 & - & - & - & - & 0 & 0 & No \\
\hline
\end{tabular}

Table 5. Pre-level weights of acquisition for student $\mathrm{G}$ geometric thinking

\begin{tabular}{|c|c|c|c|c|c|c|c|c|c|c|c|c|c|}
\hline \multirow{2}{*}{ Student ID } & \multirow{2}{*}{ Levels } & \multicolumn{10}{|c|}{ Items } & Mean & \multirow{2}{*}{ Degree } \\
\hline & & 1 & 2 & 3 & 4 & 5 & 6 & 7 & 8 & 9 & 10 & & \\
\hline \multirow[t]{3}{*}{ Student G } & One & 100 & 100 & 100 & 100 & 100 & 100 & 100 & 100 & 100 & 100 & 100 & Complete \\
\hline & Two & - & - & 25 & 25 & 0 & - & - & 25 & 25 & 0 & 17 & Low \\
\hline & Three & - & - & -- & - & 0 & - & - & - & - & 0 & 0 & No \\
\hline
\end{tabular}


Table 6. Final (post) level of student A weights of acquisition for van Hiele levels geometric thinking

\begin{tabular}{|c|c|c|c|c|c|c|c|c|c|c|c|c|c|}
\hline \multirow{2}{*}{ Student ID } & \multirow{2}{*}{ Levels } & \multicolumn{9}{|c|}{ Items } & \multirow{2}{*}{ Mean } & \multirow{2}{*}{ Degree } \\
\cline { 3 - 16 } & & 1 & 2 & 3 & 4 & 5 & 6 & 7 & 8 & 9 & 10 & & \\
\hline Student A & One & 100 & 100 & 100 & 100 & 100 & 100 & 100 & 100 & 100 & 100 & 100 & Complete \\
\hline & Two & - & - & 100 & 100 & 0 & - & - & 100 & 100 & 0 & 100 & complete \\
\hline & Three & - & - & -- & - & 100 & - & - & - & - & 100 & 100 & complete \\
\hline
\end{tabular}

Table 7. Summary of students' van Hiele level of acquisition at initial (pre)interview

\begin{tabular}{|c|c|c|c|c|c|c|}
\hline VH-iSTEM group & $\begin{array}{c}\text { Van Hiele } \\
\text { levels }\end{array}$ & No acquisition & Low acquisition & $\begin{array}{c}\text { Intermediate } \\
\text { acquisition }\end{array}$ & High acquisition & $\begin{array}{c}\text { Complete } \\
\text { acquisition }\end{array}$ \\
\hline \multirow{3}{*}{ Student A } & 1 & & & & & $\sqrt{ }$ \\
\hline & 2 & & $\sqrt{ }$ & & & \\
\hline & 3 & $\sqrt{ }$ & & & & \\
\hline \multirow{3}{*}{ Student B } & 1 & & & & & $\sqrt{ }$ \\
\hline & 2 & & $\sqrt{ }$ & & & \\
\hline & 3 & $\sqrt{ }$ & & & & \\
\hline \multirow{3}{*}{ Student C } & 1 & $\sqrt{ }$ & & & & \\
\hline & 2 & $\sqrt{ }$ & & & & \\
\hline & 3 & $\sqrt{ }$ & & & & \\
\hline \multicolumn{7}{|l|}{ VH group } \\
\hline \multirow{3}{*}{ Student D } & 1 & & & & & $\sqrt{ }$ \\
\hline & 2 & & $\sqrt{ }$ & & & \\
\hline & 3 & $\sqrt{ }$ & & & & \\
\hline \multirow{3}{*}{ Student E } & 1 & & & & & $\sqrt{ }$ \\
\hline & 2 & & $\sqrt{ }$ & & & \\
\hline & 3 & $\sqrt{ }$ & & & & $\sqrt{ }$ \\
\hline \multirow{3}{*}{ Student F } & 1 & & & & & \\
\hline & 2 & & $\sqrt{ }$ & & & \\
\hline & 3 & $\sqrt{ }$ & & & & \\
\hline \multicolumn{7}{|l|}{ Control group } \\
\hline \multirow{3}{*}{ Student G } & 1 & & & & & $\sqrt{ }$ \\
\hline & 2 & & $\sqrt{ }$ & & & \\
\hline & 3 & $\sqrt{ }$ & & & & $\sqrt{ }$ \\
\hline \multirow{3}{*}{ Student H } & 1 & & & & & \\
\hline & 2 & $\sqrt{ }$ & & & & \\
\hline & 3 & $\sqrt{ }$ & & & & \\
\hline \multirow{3}{*}{ Student I } & 1 & & & & & $\sqrt{ }$ \\
\hline & 2 & & $\sqrt{ }$ & & & \\
\hline & 3 & $\sqrt{ }$ & & & & \\
\hline
\end{tabular}

However, the summary of nine students that were interviewed at pre (initial) is provided in Table 7. The results indicate that eight students achieved the complete acquisition of van Hiele level 1(visualization) and low acquisition of level 2 (analysis) and that only student $\mathrm{C}$ in the VH-iSTEM group failed to achieve the level 1 and 2. Thus, no students achieve level 3 (informal deduction) in pre-interview, seen in Figure 2 to 4 below showing the degree of acquisition of the three independent groups at the initial. 


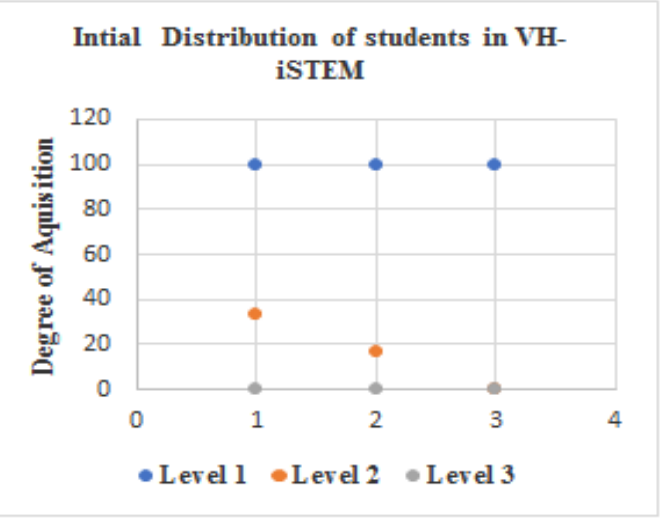

Figure 2. Scatter plot for the degree of acquisition

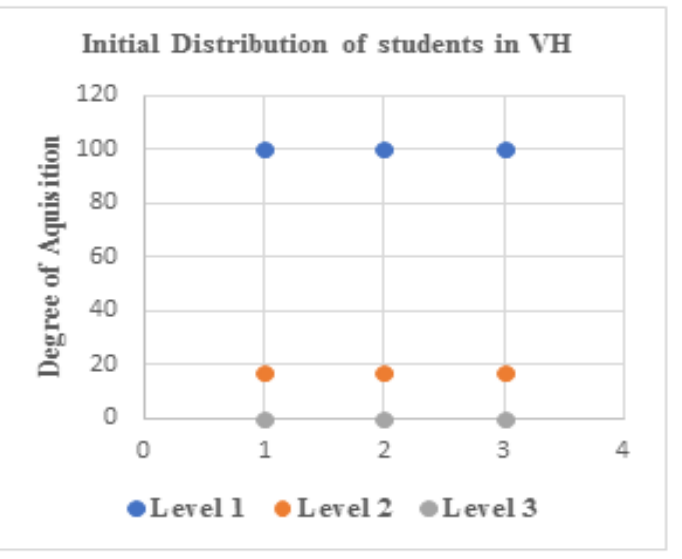

Figure 3. Scatter plot for the degree of acquisition

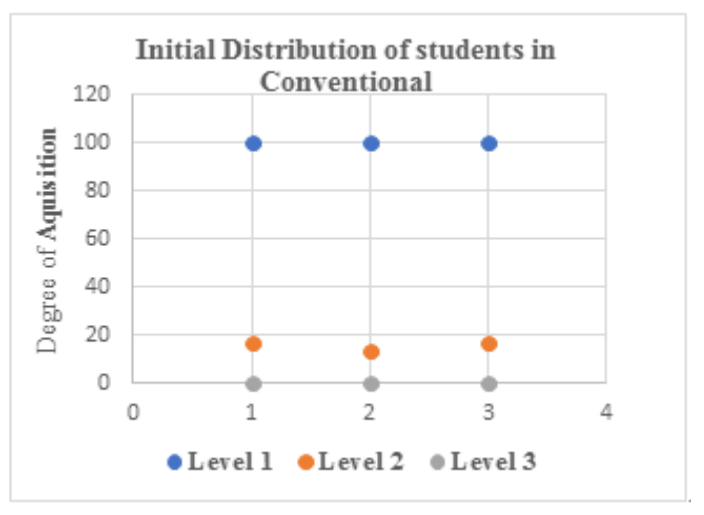

Figure 4. Scatter plot for the degree of acquisition

For the final interview, all the students in the three independent groups achieved a complete acquisition of level 1 (visualization) in the van Hiele levels. And only student $\mathrm{A}$ in VH-iSTEM achieved a complete acquisition of level 2 (analysis) and level 3 (informal deduction). Thus, five students that include student B, C, D, H and I achieved low acquisition, for the level 2 (analysis) and that student $\mathrm{E}$ achieved an intermediate acquisition on level 2 (analysis) while student $\mathrm{F}$ achieved high acquisition. For level 3 (informal deduction) a low acquisition was achieved by students B, C, D, and E., and that student $\mathrm{F}$ achieved higher acquisition on level 3. The students $(\mathrm{G}, \mathrm{H}$, and $\mathrm{I})$ in the control failed to achieved level 3 (see Table 11) for the summary of the students' levels.

Table 8. Summary of students' van Hiele level of acquisition at final (post)interview

\begin{tabular}{|c|c|c|c|c|c|c|}
\hline VH-iSTEM group & $\begin{array}{c}\text { Van Hiele } \\
\text { levels }\end{array}$ & No acquisition & Low acquisition & $\begin{array}{c}\text { Intermediate } \\
\text { acquisition }\end{array}$ & $\begin{array}{c}\text { High } \\
\text { acquisition }\end{array}$ & $\begin{array}{c}\text { Complete } \\
\text { acquisition }\end{array}$ \\
\hline \multirow{3}{*}{ Student A } & 1 & & & & & $\sqrt{ }$ \\
\hline & 2 & & & & & $\sqrt{ }$ \\
\hline & 3 & & & & & $\sqrt{ }$ \\
\hline \multirow{3}{*}{ Student B } & 1 & & & & & $\sqrt{ }$ \\
\hline & 2 & & $\sqrt{ }$ & & & \\
\hline & 3 & & $\sqrt{ }$ & & & \\
\hline \multirow{3}{*}{ Student C } & 1 & & & & & $\sqrt{ }$ \\
\hline & 2 & & $\sqrt{ }$ & & & \\
\hline & 3 & & $\sqrt{ }$ & & & \\
\hline \multicolumn{7}{|l|}{ VH group } \\
\hline \multirow{3}{*}{ Student D } & 1 & & & & & $\sqrt{ }$ \\
\hline & 2 & & $\sqrt{ }$ & & & \\
\hline & 3 & & $\sqrt{ }$ & & & \\
\hline \multirow{3}{*}{ Student E } & 1 & & & & & $\sqrt{ }$ \\
\hline & 2 & & & $\sqrt{ }$ & & \\
\hline & 3 & & $\sqrt{ }$ & & & \\
\hline \multirow{3}{*}{ Student F } & 1 & & & & & $\sqrt{ }$ \\
\hline & 2 & & & & $\sqrt{ }$ & \\
\hline & 3 & & & & $\sqrt{ }$ & \\
\hline \multicolumn{7}{|l|}{ Control group } \\
\hline \multirow{3}{*}{ Student G } & 1 & & & & & $\sqrt{ }$ \\
\hline & 2 & & $\sqrt{ }$ & & & \\
\hline & 3 & $\sqrt{ }$ & & & & \\
\hline \multirow{3}{*}{ Student $\mathrm{H}$} & 1 & & & & & $\sqrt{ }$ \\
\hline & 2 & & $\sqrt{ }$ & & & \\
\hline & 3 & $\sqrt{ }$ & & & & \\
\hline \multirow{3}{*}{ Student I } & 1 & & & & & $\sqrt{ }$ \\
\hline & 2 & & $\sqrt{ }$ & & & \\
\hline & 3 & $\sqrt{ }$ & & & & \\
\hline
\end{tabular}


The following figures provide the scatter graph of the three independent groups showing the levels of acquisitions obtained after intervention based on the interview results. Indicating improvements of students in VH-iSTEM and VH group with complete and higher acquisition respectively in achieving level three.

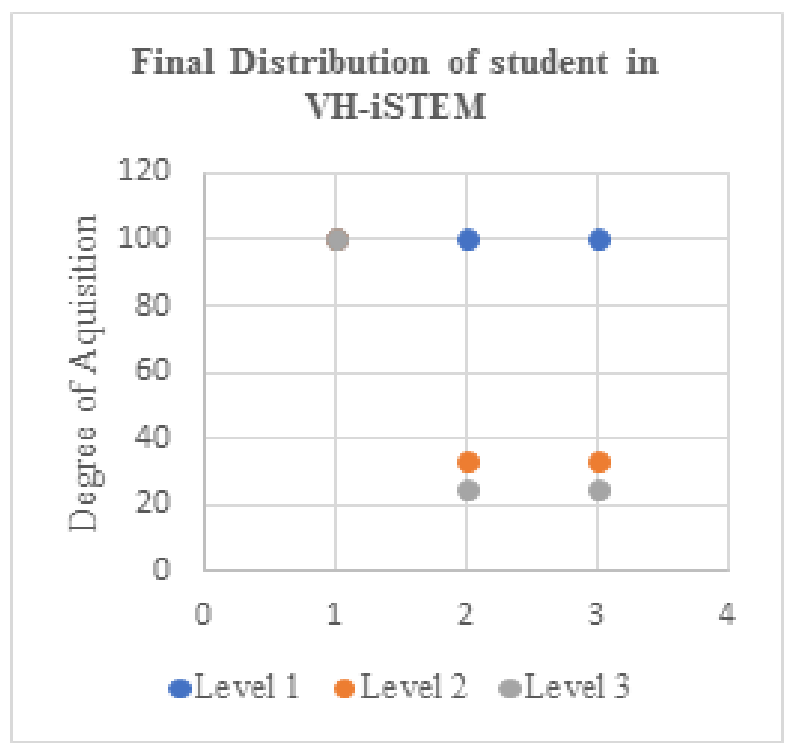

Figure 5. Scatter plot for the degree of acquisition

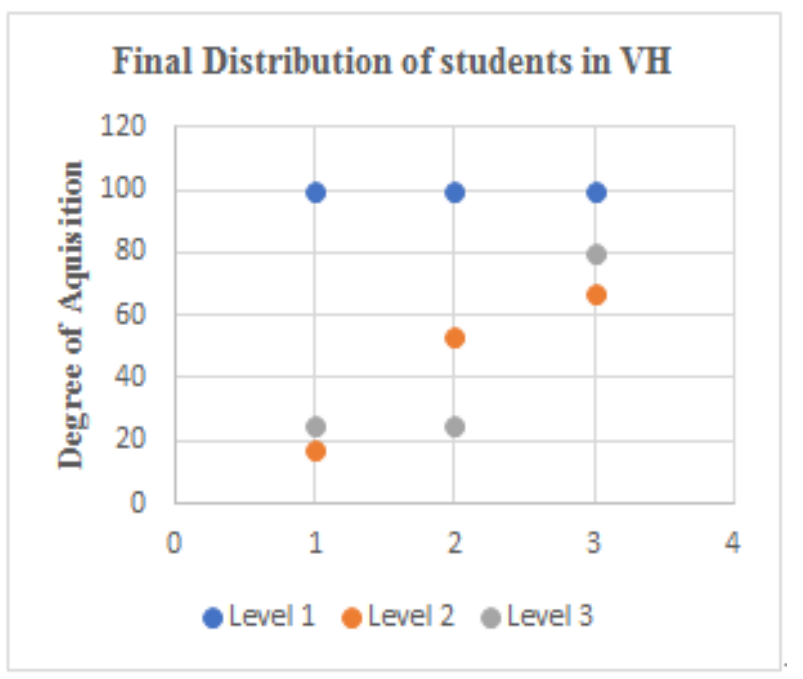

Figure 6. Scatter plot for the degree of acquisition

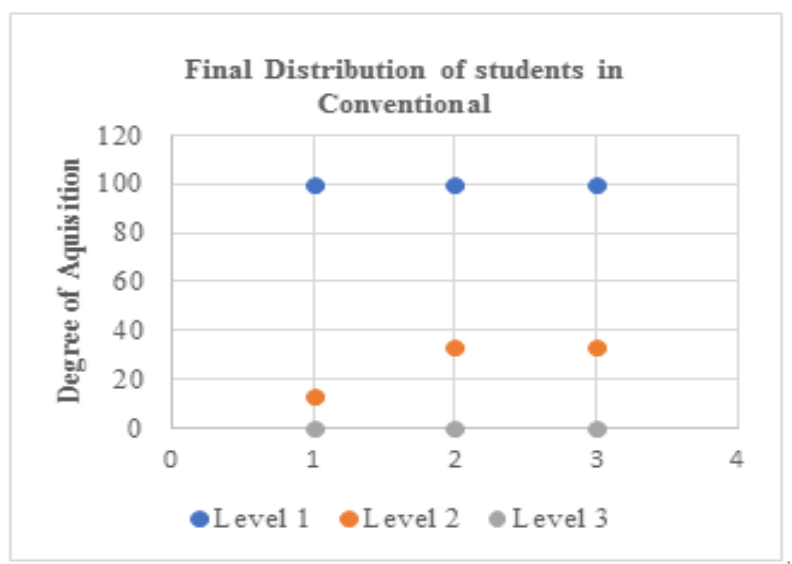

Figure 7. Scatter plot for the degree of acquisition

\section{Discussion}

In this section discussion of findings and possible interpretations of the results are provided. The results obtained from the initial (pre) interview, based on the students' degree of acquisition of van Hiele levels (vHL) of geometric thinking (GT), prior to the intervention indicates that the majority of the selected students among the three independent groups achieved the complete acquisition of the first level of van Hiele. The result obtained matched with the result of Abdullah \& Zakaria,[23], [24] that the majority of the students are found to achieve the first level of van Hiele levels and obtained a complete acquisition of the level 1. Although some students failed to achieve level 1 of geometric thinking operating at the pre-recognition level, which agrees with the previous study that confirmed the existence of students at the pre-recognition level [2], [16], [25].

However, the pre-recognition level demonstrated by the students in Sokoto state Nigeria could be as a result of the instruction received in the previous level of education. Evidence bound that the learning process is conventional in Nigeria and Sokoto state in particular and also connected to the problem of mismatch [5]. This kind of the learning process creates a gap in students' levels of GT from lower to higher levels as such students cannot develop geometric thinking as developed by Euclid [26]. 
Furthermore, the result after the intervention indicates an increment of students' degree of acquisition from lower acquisition to complete acquisition. Thus, students in the experimental groups achieved up to level three with the higher and complete acquisition in the VH-iSTEM group. And that students in the control group indicate imprecise terminology when describing geometric shapes, providing the characteristics as well as the relationship among shapes and can only achieve level 2 at low acquisition.

The finding is consistent with earlier related work conducted with basic secondary school and other research conducted in line with the van Hiele levels of geometric thinking (Abdullah, Surif, Tahir, Ibrahim, \& Zakaria, 2015; Alex \& Mammen, 2016b; Chua, Tengah, Shahrill, Tan, \& Leong, 2017). The successful improvement of students in the experimental groups based on the degree of acquisition is basically as a result of the instruction not depend on age or maturity [30]-[32]. Other factors responsible for students' improvement are the challenge activities based on the engineering design phase (EDP) connected with the van Hiele phase as provided in the VH-iSTEM learning strategy. This match with Pugalenthi,[33] that indicated EDP can improve students' understanding of geometric concepts and Mathematics in general. EDP can nature students' thinking skills [34]. Also, the iSTEM approach is one of the promising strategies use in the $21^{\text {st }}$ century [35].

The findings accord with the results obtained from the researches guided by the van Hiele phase of learning [16], [36]. Our findings indicate that the VH-iSTEM strategy is a promising means of improving GT of students. Evidence bound that [19], [34], [37] learning strategy that engages students with challenging activities, discussions, and sharing of ideas helps students to develop vocabulary and easily understand geometric concepts. Literature indicates that successful achievement in learning is dependent on the effective learning strategy used [38].

\section{Limitations}

The findings from this research indicate that the students' degree of the acquisition of van Hiele level can improve when the VH-iSTEM learning strategy is used. Despite the achievements obtained some limitations were considered in making generalizations. Some of the limitations in this study were, only basic secondary schools and the three levels of van Hiele levels thinking are considered. Therefore, the achievement obtained could not directly be applied to all levels and content other than content (plane shapes) covered or to other knowledge domain in school geometry.

Furthermore, only the basic secondary school students, consider, therefore, generalization could not be possible to other levels of students.

\section{Implication}

The important implication gained is the potential of the connection made by integrating iSTEM (Engineering Design Phase) with van Hiele to help students to improve their geometric thinking skills. More so, a guide to other researchers in the area of STEM and Mathematics in particular

\section{Conclusions}

The present research aims to investigate the effectiveness of the VH-iSTEM learning strategy based on students' degree of the acquisition on the van Hiele levels of thinking. Thus, three objectives based on plane (Triangles and quadrilaterals) geometry of the Nigerian Basic Secondary School Mathematics curriculum are involved. The results of this study indicate that students that use VH-iSTEM learning strategy can achieve complete acquisition of level three in the van Hiele levels of thinking. Therefore, following national policy on education in Nigeria, teaching should be experiential, as such teachers should use those approaches that have the potential to involve the students to actively discover learning experience by themself. Thus, the VH-iSTEM learning strategy has the potential to provide the students with the opportunity to discover the learning experience actively and also the potential to improve the students' geometric thinking skills.

\section{REFERENCES}

[1] F. Federal Republic of Nigeria, Senior Secondary School Mathematics Curriculum Printed by NERDC, Sheda Abuja Nigeria. WAEC: Nigerian Educational Research and Development Council, (NERDC), 2012.

[2] H. Atebe, "Students' Van Hiele Levels of Geometric Thought and Conception in Plane Geometry : a Collective Case Study of Nigeria and South Africa," RHODES UNIVERSITY, 2008.

[3] D. S. Allen and S. Martinie, "Geometry: More than Just Shapes," Math. Teach. Middle Sch., vol. 12, no. 2, pp. 100$101,2006$.

[4] (NCTM) National Council of Teachers of Mathematics, Principles, and Standards for School Mathematics. United States of America: The National Council of Teachers of Mathematics, Inc, 2000.

[5] H. U. Atebe and M. Schäfer, "The nature of geometry instruction and observed learning-outcomes opportunities in Nigerian and South African high schools," African J. Res. Math. Sci. Technol. Educ., vol. 15, no. 2, pp. 191-204, 2011.

[6] M. A. Yusha'u, "Effective Use of Teaching Methodologies in Science, Technology, and Mathematics (STM) Classroom 
in Nigeria: A Panacea to Vision 20 : 2020," Int. J. Educ. Pract., vol. 3, no. 3, pp. 114-121, 2015.

[7] B. I. Nwoke, "Enhancing Secondary School Students' Achievement in Mathematics Using Peer Tutoring Instructional Approach," Abacus, The J. Math. Assoc. Nriaige, vol. 42, no. 1, pp. 406-416, 2017.

[8] E. C. Unamba, O. M. Nwaneri, and N. Nelson, "Effectiveness of Brain-Based Learning Approach on Pupils Academic Achievement in Mathematics," Abacus, The J. Math. Assoc. Nriaige, vol. 42, no. 1, pp. 551-559, 2017.

[9] Samuel O. Ugboduma, "Effectiveness of ADDIE Instructional Model Designed Based on Interest of Senior Secondary School students in Geometry," Abacus, The J. Math. Assoc. Nriaige, vol. 42, no. 2, pp. 176-182, 2017.

[10] A. W. Rohani, A. Abdul Halim, A. Mohd Salleh, M. Mahani, and A. Noor Azean, "A Case Study on Visual-Spatial Skills and Level of Geometric Thinking in Learning 3D Geometry Among High Achievers," Man India, vol. 96, no. 1-2, pp. 489-499, 2015.

[11] F. Lipowsky, K. Rakoczy, C. Pauli, B. Drollinger-vetter, E. Klieme, and K. Reusser, "Quality of geometry instruction and its short-term impact on students ' understanding of the Pythagorean Theorem," Learn. Instr., vol. 19, no. 6, pp. 527-537, 2009.

[12] Z. Usiskin, "Van Hiele Levels and Achievement in Secondary School Geometry. CDASSG Project." Chicago USA, p. 321, 1982.

[13] R. A. Wahab, A. H. Abdullah, M. Mokhtar, N. A. Atan, and M. S. Abu, "Evaluation by experts and designated users on the learning strategy using SketchUp make for elevating visual-spatial skills and geometry thinking," Bolema - Math. Educ. Bull., vol. 31, no. 58, pp. 819-840, 2017.

[14] H. T. N. Rizki, D. Frentika, and A. Wijaya, "Exploring students' adaptive reasoning skills and van Hiele levels of geometric thinking: a case study in geometry Exploring students ' adaptive reasoning skills and van Hiele levels of geometric thinking : a case study in geometry," J. Phys., vol. 983, confe, pp. 1-6, 2018.

[15] J. K. Alex and K. J. Mammen, "Lessons Learnt from Employing van Hiele Theory-Based Instruction in Senior Secondary School Geometry Classrooms," EURASIA J. Math. Sci. Technol. Educ., vol. 12, no. 10, pp. 2223-2236, 2016.

[16] A. S. Mdyunus, A. F. M. Ayub, and T. T. Hock, "Geometric Thinking of Malaysian Elementary School Students," Int. J. Instr., vol. 12, no. 1, pp. 1095-1112, 2019.

[17] N. Wonu and I. G. Zalmon, "Diagnosis and Remediation of Senior Secondary Students' Common Learning Difficulties in Mathematics From Chief Examiners' Report," Eur. J. Res. Reflect. Educ. Sci., vol. 5, no. 1, pp. 7-23, 2017.

[18] H. U. Atebe and M. Schäfer, "“As soon as the four sides are all equal, then the angles must be $90^{\circ}$ each'. children's misconceptions in geometry," African J. Res. Math. Sci. Technol. Educ., vol. 12, no. 2, pp. 47-65, 2008.

[19] J. Van de Walle, "Geometric thinking and geometric concepts," in Elementary and Middle school mathematics: Teaching developmentally., 4th ed., Boston.Allyn and Bacon,
Eds. Pearson Education, 2001, pp. 306-312.

[20] D. T. Campbell and J. C. Stanley, "Experimental and Quasi-Experimental Desing for Research," in Handbook of Research on Teaching, All rights., N. L. Gage (Editor), Ed. United States of America: Houghton Mifflin Company, 1963, pp. 1-84.

[21] B. Johnson and C. Larry, Educational Research: Quantitative, Qualitative, and Mixed Approaches, 5th ed. United States of America: SAGE Publications, Inc., 2014.

[22] A. Gutierrez, U. De Valencia, A. Jaime, U. De Valencia, J. M. Fortuny, and U. A. De Barcelona, "An Alternative Paradigm to Evaluate the Acquisition of the van Hiele Levels," Res. Math. Educ., vol. 22, no. 3, pp. 237-251, 1991.

[23] A. H. Abdullah and E. Zakaria, "Enhancing students' level of geometric thinking through van hiele's phase-based learning," Indian J. Sci. Technol., vol. 6, no. 5, pp. 4432 4446, 2013.

[24] A. H. Abdullah and E. Zakaria, "The Effects of Van Hiele's Phases of Learning Geometry on Students' Degree of Acquisition of Van Hiele Levels," Procedia - Soc. Behav. Sci., vol. 102, no. Ifee 2012, pp. 251-266, 2013.

[25] D. H. Clements and M. T. Battista, "Geometry and Spatial Reasoning: Handbook of Research on Mathematics Teaching and Learning." Macmillan, New York, p. 464, 1992.

[26] P. M. van Hiele, "Developing Geometric Thinking Activities That Begin with Play," J. Natl. Counc. Teach. Math., vol. 5, no. 6, pp. 310-316, 1999.

[27] H. M. Nasiru, A. H. Abdullah, and I. Norulhuda, "Design and Development of VH-iSTEM Learning Strategy on Geometric Thinking: An Experts' Evaluation," Int. J. Recent Technol. Eng., vol. 8, no. 3S2, pp. 723-732, 2019.

[28] A. H. Abdullah, J. Surif, L. M. Tahir, N. H. Ibrahim, and E. Zakaria, "Enhancing students' geometrical thinking levels through Van Hiele's phase-based Geometer's Sketchpad-aided learning," in 2015 IEEE 7th International Conference on Engineering Education, ICEED 2015, 2015, no. 4, pp. 106-111.

[29] G. L. L. Chua, K. A. Tengah, M. Shahrill, A. Tan, and E. Leong, "Analysing Students' Perspectives on Geometry Learning from the Combination of van Hiele Phase-Based Instructions and Geogebra," in Proceeding of the 3rd International Conference on Education, 2017, no. 31, pp. 205-213.

[30] I. Noraini, "The Effect of Geometers' Sketchpad on the Performance in Geometry of Malaysian Students' Achievement and van Hiele Geometric Thinking," Malaysian J. Math. Sci. 1(2), vol. 1, no. 2, pp. 169-180, 2007.

[31] C. C. Meng and I. Noraini, "Enhancing Students' Geometric Thinking and Achievement in Solid Geometry," J. Math. Educ. CEducation All, vol. 5, no. 1, pp. 15-33, 2012.

[32] A. H. Abdullah and E. Zakaria, “Students' perceptions towards the Van Hiele's phases of learning geometry using Geometer's Sketchpad software," Aust. J. Basic Appl. Sci., vol. 5, no. 7, pp. 787-792, 2011.

[33] P. Pugalenthi, "Integration of Engineering in a 
Middle-Grade Mathematics Classroom: A conceptual Framework for Science, Technology, Engineering and Mathematics (STEM) Integration," University of North Carolina at Charlotte, 2019.

[34] (NCSM) National Council of Supervisors of Mathematics and (NCTM) National Council of Teachers of Mathematics, "Building STEM Education on a Sound Mathematical Foundation," in National Council of Teachers of Mathematics, 2018, pp. 1-8.

[35] S. Ardianti, D. Sulisworo, Y. Pramudya, and W. Raharjo, "The Impact of the Use of STEM Education Approach on the Blended Learning to Improve Student's Critical Thinking Skills," Univers. J. of educational Res., vol. 8, no. 3B, pp. 24-32, 2020.

[36] J. K. Alex and K. J. Mammen, "Geometrical Sense-Making:
Findings of Analysis Based on the Characteristics of the van Hiele Theory among a Sample of South African Grade 10 learners," Eurasia J. Math. Sci. Technol. Educ., vol. 12, no. 2, pp. 173-188, 2016.

[37] A. H. Abdullah, N. H. Ibrahim, J. Surif, and E. Zakaria, "The effects of Van Hiele's phase-based learning on students' geometric achievement and attitude towards geometry," in Proceedings - 2014 International Conference on Teaching and Learning in Computing and Engineering, LATICE 2014, 2014, pp. 317-324.

[38] N. Sa, S. A. Kadir, A. Abdullah, and S. N. Alias, "Learning Strategy and Higher Order Thinking Skills of Students in Accounting Studies : Correlation and Regression Analysis," Univers. J. of educational Res., vol. 8, no. 3c, pp. 85-90, 2020. 